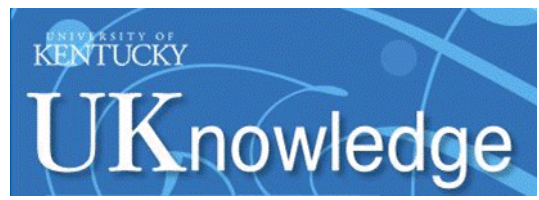

University of Kentucky

UKnowledge

\title{
Load Variation Reduction by Aggregation in a Community of Rooftop PV Residences
}

\author{
Huangjie Gong \\ University of Kentucky, huangjie.gong@uky.edu \\ Vandana Rallabandi \\ University of Kentucky, vandana.rallabandi@uky.edu \\ Dan M. Ionel \\ University of Kentucky, dan.ionel@uky.edu
}

Follow this and additional works at: https://uknowledge.uky.edu/peik_facpub

Part of the Power and Energy Commons

Right click to open a feedback form in a new tab to let us know how this document benefits you.

\section{Repository Citation}

Gong, Huangjie; Rallabandi, Vandana; and Ionel, Dan M., "Load Variation Reduction by Aggregation in a Community of Rooftop PV Residences" (2019). Power and Energy Institute of Kentucky Faculty Publications. 18.

https://uknowledge.uky.edu/peik_facpub/18

This Conference Proceeding is brought to you for free and open access by the Power and Energy Institute of Kentucky at UKnowledge. It has been accepted for inclusion in Power and Energy Institute of Kentucky Faculty Publications by an authorized administrator of UKnowledge. For more information, please contact UKnowledge@lsv.uky.edu. 


\title{
Load Variation Reduction by Aggregation in a Community of Rooftop PV Residences
}

\author{
Digital Object Identifier (DOI) \\ https://doi.org/10.1109/PESGM40551.2019.8974029
}

Notes/Citation Information

Published in 2019 IEEE Power \& Energy Society General Meeting (PESGM).

(C) 2019 IEEE Copyright Notice. "Personal use of this material is permitted. Permission from IEEE must be obtained for all other uses, in any current or future media, including reprinting/republishing this material for advertising or promotional purposes, creating new collective works, for resale or redistribution to servers or lists, or reuse of any copyrighted component of this work in other works."

The document available for download is the authors' manuscript version that is accepted for publication. The final published version is copyrighted by IEEE and will be available as: H. Gong, V. Rallabandi and D. M. Ionel, "Load Variation Reduction by Aggregation in a Community of Rooftop PV Residences," 2019 IEEE Power \& Energy Society General Meeting (PESGM), Atlanta, GA, USA, 2019, pp. 1-4, doi:10.1109/ PESGM40551.2019.8974029. 


\title{
Load Variation Reduction by Aggregation in a Community of Rooftop PV Residences
}

\author{
Huangjie Gong, Vandana Rallabandi, and Dan M. Ionel \\ SPARK Laboratory, Department of Electrical and Computer Engineering, University of Kentucky, Lexington, KY, US \\ huangjie.gong@uky.edu, vandana.rallabandi@uky.edu,dan.ionel@uky.edu
}

\begin{abstract}
This paper performs computational studies and develops control schemes for a virtual power plant (VPP) network formed by a community of homes with rooftop solar PV generation, and battery energy storage. Appropriate control and scheduling of the battery operations, and peer-peer power flow between the homes provide a possible solutions for reducing the higher costs and uncertainties brought to grid by high solar PV penetration. The residential community studied here includes twelve homes categorized into four types depending on whether they have energy storage or rooftop solar PV panels. The homes exchange power among themselves, and the real-time electricity rate and the energy assignment for each are decided based on their individual bidding schemes. The homes benefit due to the lower electricity rate enabled by this aggregation, as compared with that available from the utility grid. In this work, the PV generation and load consumption for the different types of homes are calculated from building models. Simulation studies demonstrate that the advantages of the proposed transactive power flow include lower maximum power demand as well as reduced peak-peak power on the duck curve.
\end{abstract}

Keywords-Virtual Power Plant (VPP); Aggregation; Battery Control Scheme; Time of Use Rate; Smart Home.

\section{INTRODUCTION}

Data from the U.S. Energy Information Administration shows that the hourly load demand grew by $14 \%$ in 2018 compared with a year before [1]. Furthermore, with the increasing PV penetration, and considering that peak load and generation are not coincident, excess power is supplied to the utility grid causing the "duck curve" phenomenon especially in neighborhoods where roof-topped PV panels are congregated [2], [3]. The increasing power demand and PV penetration further exacerbate the issue, and necessitate upgrading the ratings of distribution equipment, and possibly generation and transmission capacity expansion.

The distribution power system containing homes with rooftop PV panels and batteries can be regarded as a virtual power plant (VPP), according to its definition that a VPP is a set of generating units, storage facilities, and demands, that are grouped and operate as a single entity with the aim of optimizing the energy resources [4], [5]. The utility grid benefits from the VPP because of its ability to tackle the uncertainties in renewable energy generation and fluctuation in the system power demand [6]. The VPP operates as a proactive market player who purchases or sells active power at the utility level, leading to desirable power flow [7], [8].

At the lower intramarket level within the VPP, one way to encourage customers to coordinate is aggregation [9]. Cus- tomers change their net power demand profiles by controlling the residential batteries, which supply electricity when the aggregated demand is high and absorb power when PV generation is in surplus. As the electricity rate from the aggregator changes according to the amount of energy residences are willing to sell or buy, the customers who are able to coordinate gain the financial benefits [10].

In this paper, the power flow from the VPP is dynamically calculated based on the net demand and power flow among different homes. EnergyPlus is employed for modeling the realtime energy consumption and generation from each house. The power absorbed or supplied by each home is decided based on the individual bidding schemes. This paper demonstrates that benefits of aggregation including peak power reduction, are achieved even in areas with fixed electricity rates.

This paper studies the beneficial effects of aggregation, including reductions in peak power demand for the VPP load profile. A subdivision including different types of homes is modeled and controlled as a VPP. Four types of homes are distinguished by the combination of PV and battery energy storage (BES) availability. Representative case studies for one summer day and one winter day are evaluated.

\section{System Modeling}

A VPP is comprised by a system with 12 homes, including some with rooftop PV sources and batteries (Fig. 1). It is assumed that this residential community is connected to the grid via one node, which is regarded as an infinite source. In this paper, only active power flow is considered in the network and the power at the grid node is obtained from the generation and load demand of all homes. Transactive power flow behind the node is enabled by the aggregator.

The 12-homes are categorized into four different types based on the availability of BES and PV. They are: homes without solar PV or BES; those with only BES but no PV; houses with $\mathrm{PV}$ alone and residencies having both PV and BES, with the abbreviations 'Conventional', 'BES only', 'PV only', 'BES and PV', respectively. Each of the four categories has three homes, with different load profiles. The loads are denoted by $L_{1}, L_{2}, L_{3}$ for winter, and $L_{4}, L_{5}, L_{6}$ for summer (Fig. 2). The power demand is calculated from building energy models developed in BEopt and EnergyPlus, with weather data from Sacramento, CA.

The net load of each home is decided by its own power demand, the PV generation, the BES power and the power 


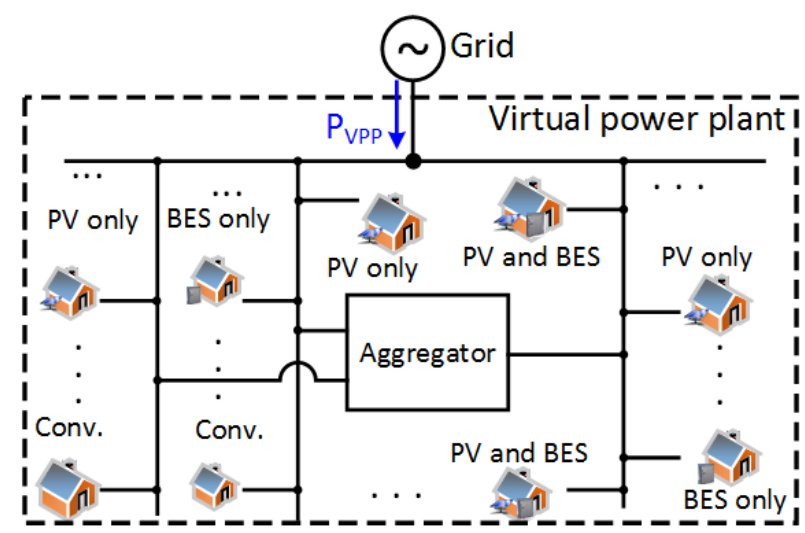

Figure 1. Schematic of the studied VPP system composed by homes with rooftop PV generation and residential battery storage. The VPP control is realized by the transactive power flow, which is enabled by the aggregator. The power system includes four types of homes, namely, 'conventional' households without either BES or PV panels, homes having BES only, those with PV only but no BES, and residences equipped with both PV and BES.

from the aggregator. The net power demand of each home supplied by the grid is given by,

$$
P_{G}(t)=P_{H}(t)-P_{P V}(t)-P_{B E S}(t)-P_{A}(t),
$$

where $P_{G}(t)$, power from the grid; $P_{H}(t)$, home power demand; $P_{P V}(t)$, the PV generation; $P_{B E S}(t)$, BES power; $P_{A}(t)$, power from the aggregator. The total power delivered to the VPP from the grid node is calculated as,

$$
P_{V P P}(t)=\sum_{1}^{i} P_{G}^{i}(t), \quad i=1,2, \ldots, n,
$$

where $P_{G}^{i}$ is the net power of home $i$ calculated in (1).

\section{Home Bidding Schedules}

Transactive power flow among the houses allows them to perform energy arbitrage behind the grid node. The aggregator is responsible for setting the real-time electricity rate and energy distribution based on the bidding schemes from each home, which describe the relationship between the amount energy bought and the electricity rate. The proposed bidding scheme is SOC based such that houses buy power when the SOC is low, and sell power when it is high. The bidding scheme is defined as follows,

$$
E_{i}=a_{i} \cdot r_{i}+b_{i}, \quad i=1,2, \ldots, n,
$$

where $E_{i}$, the energy home $i$ buys from the aggregator; $r_{i}$, the electricity rate; $a_{i}$ and $b_{i}$ are coefficients. The coefficients change dynamically in time and for different houses.

Knowing the utility electricity rate and the energy allowed to be traded at any given time, the coefficients are calculated based on the SOC. For example, the line standing for SOC $=50 \%$ in the middle in the graph of Fig. 4 is defined by points $\left(r_{s}, E_{\max }\right)$ and $\left(r_{b},-E_{\max }\right)$, where $r_{s}, r_{b}$, the rates offered by the grid to the houses for selling and buying electricity, respectively and $E_{\max }$ is the maximum energy

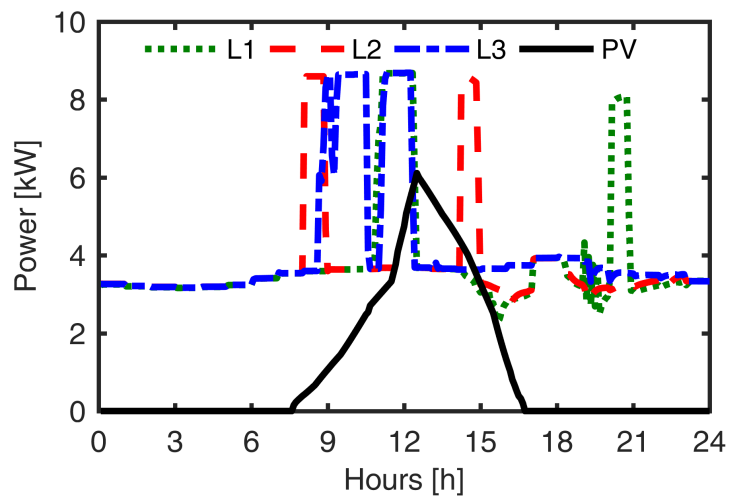

(a)

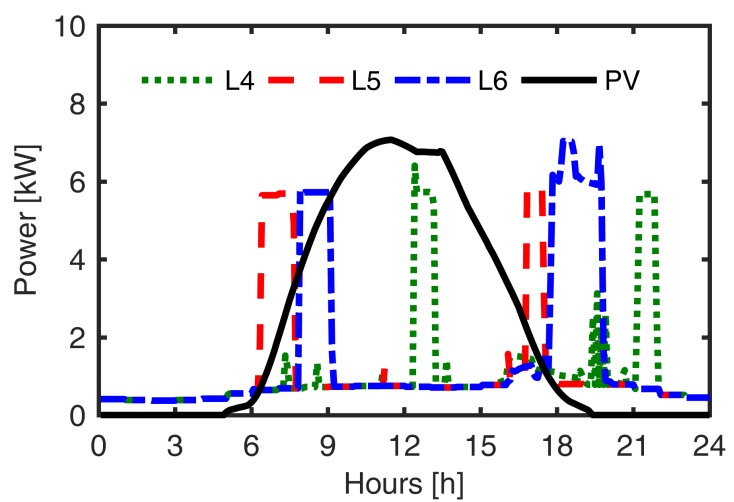

(b)

Figure 2. Power consumption and PV generation for different homes on a winter day (a); a summer day (b). The power demands are calculated with detailed building energy models realized by BEopt and EnergyPlus. Houses equipped with solar panels are assumed to have the same PV generation in the same day because of the same PV rating and weather conditions.

allowed for a single house to trade, in this case, the points $(0.05,0.6)$ and $(0.15,-0.6)$. The coefficients $a_{i}$ and $b_{i}$ are calculated by solving the equation formed by these two points.

For a given house with BES, the bidding scheme changes with the variation of SOC in time. For a given time, houses with BES usually have different bidding schemes because the SOCs tend to be diverse as the twelve houses are most likely to have different power demands. Therefore, different houses always have diverse bidding schemes at one time. For homes without BES, the bidding scheme is set to the same as that of houses containing a battery with a SOC of $50 \%$.

When SOC decreases, the point $\left(r_{s}, E_{\max }\right)$ remains unchanged, while the y value of the other point increases to encourage buying energy. For instance, the point $\left(r_{b},-E_{\max }\right)$ changes to $\left(r_{b}, E_{\max }\right)$ as SOC decrease from $50 \%$ to $0 \%$ in the extreme case. On the contrary, when SOC increases from $50 \%$ to $100 \%$, the point $\left(r_{b},-E_{\max }\right)$ remains unchanged but point $\left(r_{s}, E_{\max }\right)$ changes to $\left(r_{s},-E_{\max }\right)$.

The battery power for each home is calculated from the power balance equation (1), and the bidding scheme for the next time step is updated based on the SOC. The whole procedure for aggregation is presented in Fig. 3 . 


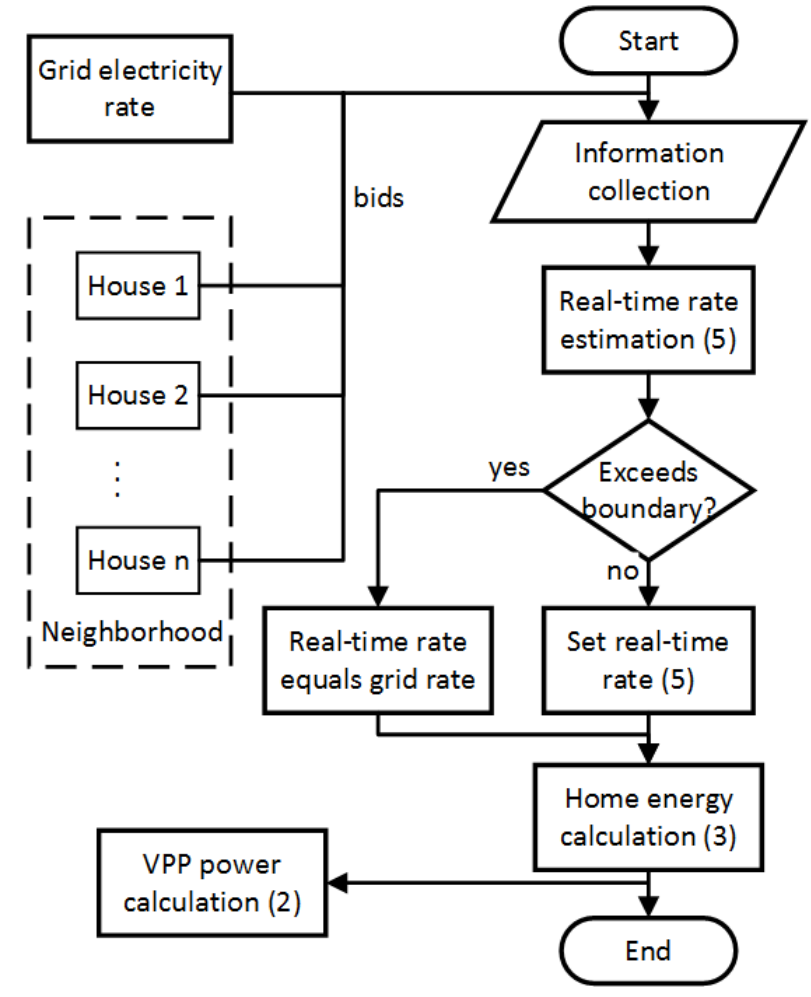

Figure 3. Procedures for aggregation at each time step. The aggregator collects the information from the grid and the homes, based on which the electricity rate and the energy distribution are calculated. The equations used for estimation are placed within the blocks in parentheses.

The total amount of energy bought from the aggregator is set to zero, assuming no loss in the arbitrage,

$$
\sum_{i=1}^{n} E_{i}=0
$$

Solving (3) and (4) acquires the real-time electricity price, as,

$$
r=-\frac{\sum b_{i}}{\sum a_{i}}, \quad i=1,2, \ldots, n, \quad r_{b}<r<r_{s},
$$

where the electricity rate from the aggregator is limited by $r_{b}$ and $r_{s}$, the rates offered by the grid to the houses for buying and selling electricity, respectively. The energy assigned to each house is decided by the electricity rate from (5) and the bidding scheme submitted by the house in (3).

\section{CAse Study}

A neighborhood with 12-homes is studied, and the dynamic power demand of the VPP comprised by these houses is analyzed on a representative winter and summer day. The BES and PV ratings in the homes are $7 \mathrm{~kW} / 20 \mathrm{kWh}$ and $10 \mathrm{~kW}$ respectively. Four cases are proposed for each of the representative days: 1) With transactive power flow or aggregation (Fig. 1); 2) without the aggregation; 3) With aggregation, but none of the homes have BES; 4) without the aggregation and with no BES in any of the homes. Without BES, the total net power demand of the VPP in cases 3 and 4 are the same,

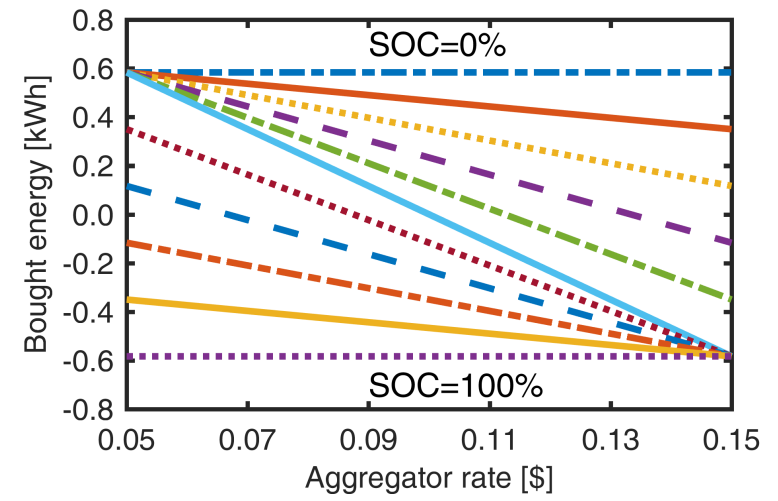

Figure 4. Bidding schemes for different battery states of charge. For a given SOC, the amount of energy bought by a home is decided by the real-time electricity rate at the aggregator. In the two limiting cases with $\mathrm{SOC}=100 \%$ and $\mathrm{SOC}=0 \%$, the home sells and buys energy, respectively, regardless of the electricity rate.

therefore, they are combined as case 'no BES', which forms the reference case. The simulation step is set to 5 minutes.

Simulation results show that both the peak-to-peak power and maximum power demand of the VPP are reduced in case 2, as compared with the reference case. The VPP performance is further improved in case 1 when there is transactive power flow among the houses.

On the studied winter day, the VPP behaves as a load (Fig. $5)$. For case 1, the power is transacted through the aggregator when the PV generation is high in the afternoon. The batteries charge from the PV system in the afternoon and supply power towards the evening hours, which reduces the peak power demand and variation (Fig. 6). The highest reduction in the peak-peak and maximum power is achieved in case 1.

The VPP in the summer sells electricity to the grid when the PV generation is high and buys it when the power demand is high (Fig. 7). In the afternoon, BESs in case 1 have access to the PV generation of all houses. Motivated by the lower electricity rate offered by the aggregator when the PV generation is abundant, BESs store greater energy in case 1 (Fig. 8). Due to the higher SOC of the BES, homes self consume, thereby reduce the total peak power in the evening.

\section{CONCLUSiON}

This paper studies a VPP formed by a community of smart homes with rooftop solar PV generation, and battery energy storage systems. The buildings' power demand and generation are modeled through BEopt and EnergyPlus. This VPP is connected to the grid, which is represented as an ideal sink or source of power. The batteries within the houses are controlled such that transactive power flow occurs behind the grid.

Case studies carried out on representative winter and summer days, for homes with and without batteries, and with and without transactive power flow reveal that the use of energy storage substantially reduces the peak-peak load variations, as well as the maximum demand. Further reductions in these quantities are achieved when the homes exchange power 


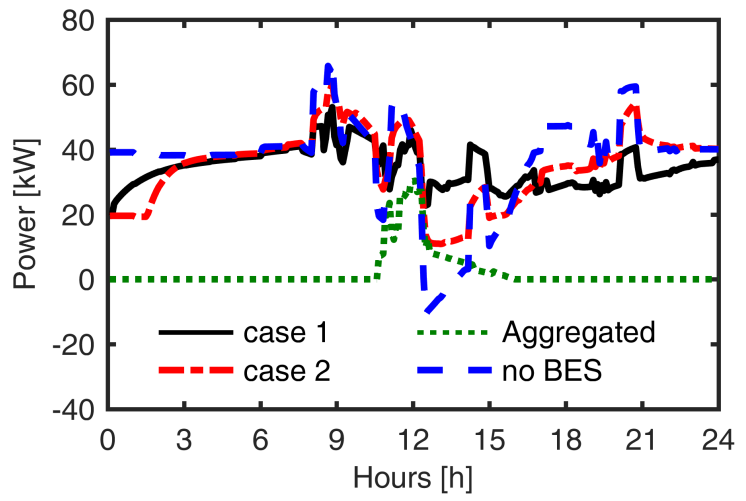

Figure 5. The real-time power for a representative winter day. 'Aggregated' stands for the power passing through the aggregator. The fluctuation and peak power demand of the VPP is mitigated by the residential BES, and further improved by the aggregator.

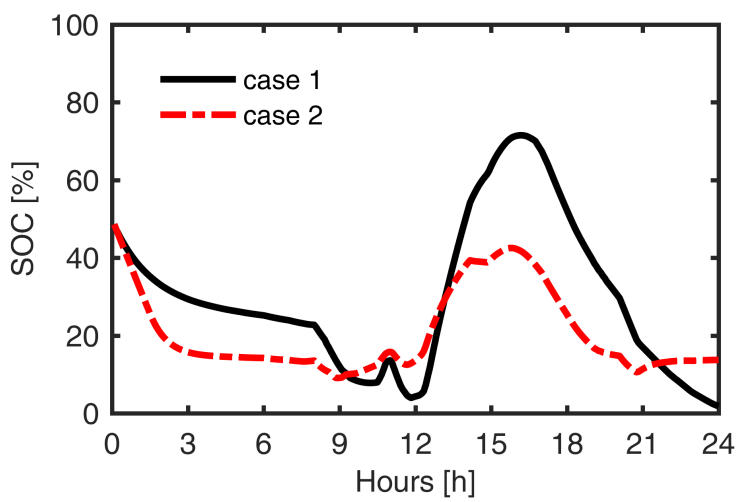

Figure 6. The available energy of the VPP on the representative winter day. The batteries charge more in the afternoon and supply higher power in the evening, leading to VPP output power with reduced maximum demand and peak-to-peak power.

among one another. Reduced load variations, and smaller maximum demands can potentially offset investment in distribution capacity expansion, and also reduce the flexibility requirements of the generation system.

\section{ACKNOWLEDGMENT}

The support of University of Kentucky, the L. Stanley Pigman endowment, and of the SPARK program and the Power and Energy Institute of Kentucky (PEIK) is gratefully acknowledged.

\section{REFERENCES}

[1] "U.S. Energy Information Administration," https://www.eia.gov/ realtime_grid/\#/summary/demand?end $=20181007 \&$ start $=20180805 \&$ frequency $=$ Weekly\&regions $=08$, accessed: $2020-6-8$.

[2] P. Denholm, M. O'Connell, G. Brinkman, and J. Jorgenson, Overgeneration from solar energy in California: a field guide to the duck chart. National Renewable Energy Laboratory Golden, CO, 2015.

[3] F. Blaabjerg and D. M. Ionel, Renewable Energy Devices and Systems with Simulations in MATLAB ${ }^{\circledR}$ and ANSYS®. CRC Press, Boca Raton, FL, 2017.

[4] J. M. Morales, A. J. Conejo, H. Madsen, P. Pinson, and M. Zugno, Integrating renewables in electricity markets: operational problems. Springer Science \& Business Media, 2013, vol. 205.

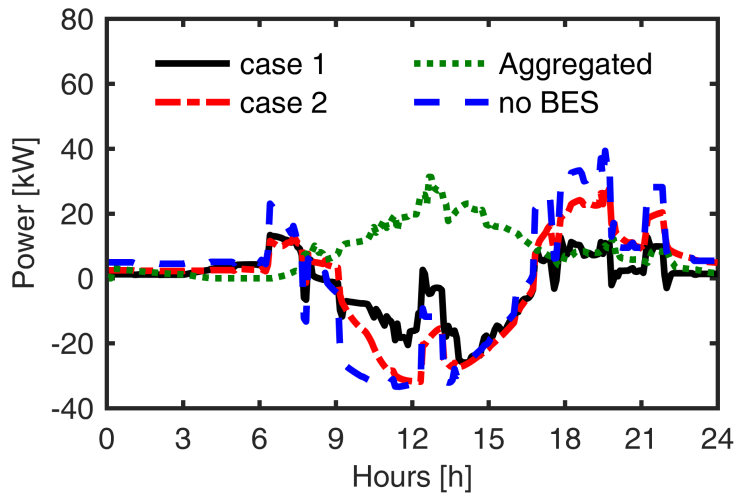

Figure 7. The total power for a representative summer day. The peak fed-in power in the afternoon and the maximum demand in the evening are reduced in both case 1 and case 2 compared with the reference case 'no BES'. The demand profile in case 1 of the VPP has reduced variations further due to the aggregation.

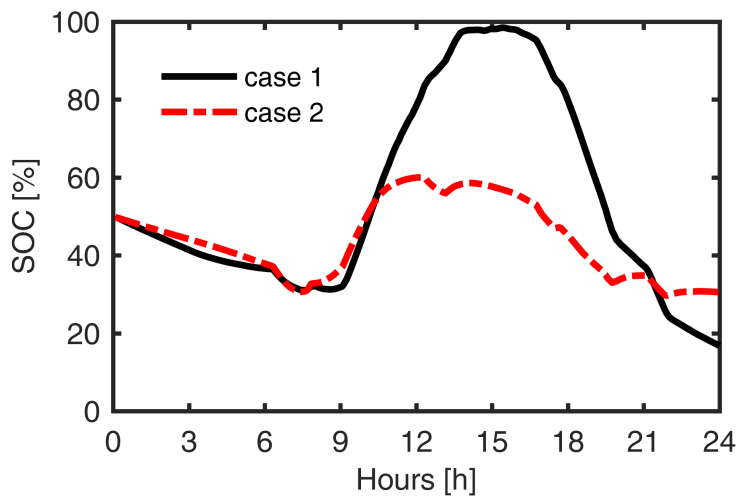

Figure 8. The available energy of the VPP in the representative summer day. Enabled by the aggregator, BESs in the afternoon buy and store more power from homes having excess PV generation. In the evening, BESs are encouraged to supply more power because of the high electricity rate decided by the aggregator.

[5] A. Baringo and L. Baringo, "A stochastic adaptive robust optimization approach for the offering strategy of a virtual power plant," IEEE Transactions on Power Systems, vol. 32, no. 5, pp. 3492-3504, 2017.

[6] K. O. Adu-Kankam and L. M. Camarinha-Matos, "Towards collaborative virtual power plants," in Technological Innovation for Resilient Systems: 9th IFIP WG 5.5/SOCOLNET Advanced Doctoral Conference on Computing, Electrical and Industrial Systems, DoCEIS 2018, Costa de Caparica, Portugal, May 2-4, 2018, Proceedings 9. Springer, 2018, pp. 28-39.

[7] C. Wei, J. Xu, S. Liao, Y. Sun, Y. Jiang, D. Ke, Z. Zhang, and J. Wang, "A bi-level scheduling model for virtual power plants with aggregated thermostatically controlled loads and renewable energy," Applied Energy, vol. 224, pp. 659-670, 2018.

[8] A. Bagchi, L. Goel, and P. Wang, "Adequacy assessment of generating systems incorporating storage integrated virtual power plants," IEEE Transactions on Smart Grid, 2018.

[9] W. Pei, Y. Du, W. Deng, K. Sheng, H. Xiao, and H. Qu, "Optimal bidding strategy and intramarket mechanism of microgrid aggregator in real-time balancing market," IEEE Transactions on Industrial Informatics, vol. 12, no. 2, pp. 587-596, 2016.

[10] H. Gong, O. Akeyo, V. Rallabandi, and D. M. Ionel, "Real time operation of smart homes with pv and battery systems under variable electricity rate schedules and transactive power flow," in 2018 7th International Conference on Renewable Energy Research and Applications (ICRERA). IEEE, 2018, pp. 1392-1395. 